\title{
A infraestrutura das escolas públicas brasileiras de pequeno porte
}

\author{
Joaquim José Soares Neto, Camila Akemi Karino, \\ Girlene Ribeiro de Jesus e Dalton Francisco de Andrade
}

\section{Introdução}

O processo de ensino-aprendizagem é complexo e exige a interação de diversos fatores para ser realizado de forma adequada. Requer desde um corpo docente qualificado até condições de infraestrutura escolar favorável, o que inclui materiais didáticos, equipamentos, e estruturas físicas apropriadas. Sem o suporte suficiente para o desenvolvimento do seu trabalho, a atuação do professor fica prejudicada, ou seja, o suporte institucional é fundamental para que o professor possa desenvolver um bom trabalho educacional.

Além das diferenças individuais e familiares dos estudantes, estudos têm mostrado que a escola pode fazer a diferença (BARBOSA \& FERnANDES, 2001; LEE, 2008). Essa concepção tem impulsionado uma série de estudos, nacionais e internacionais, a fim de identificar que características ou fatores escolares são mais eficazes para promover aprendizagem e desenvolvimento. Busca-se, assim, encontrar os "determinantes-chave" da eficácia escolar (SAMmONS, 1999). 
Vários fatores têm sido apontados na literatura como determinantes para bons resultados. Destaca-se, por exemplo, a participação dos pais na vida escolar, trajetória escolar do estudante, o nível socioeconômico, recursos técnico-pedagógicos, instalações físicas/infraestrutura, variáveis relacionadas aos professores, etc. (Andrade \& Laros, 2007; Barbosa \& Fernandes, 2001; Jesus \& Laros, 2004; SoAres, César \& Mambrini, 2001; Willms \& Somers, 2000). Esses estudos concentram-se em identificar variáveis que possam contribuir para a promoção da eficácia e da equidade da educação.

A questão da equidade no contexto brasileiro é um aspecto central. Há muitos estudos que mostram que aspectos socioeconômicos e demográficos são bastante relevantes para os resultados educacionais (LeE, 2008; SoAres \& ANDrade, 2006; SoAres; César \& Mambrini, 2001; Coleman et al., 1966). No Brasil, tamanho é o impacto das características socioeconômicas e demográficas, que vários estudos multinível trabalham esses aspectos como variáveis de controle, a fim de poder investigar outras variáveis relacionadas a aspectos intraescolares (FLETCHER, 1998; SoAres, 2004; Jesus \& Laros, 2004; ANDRADE \& LAROS, 2007).

Após controlar o nível socioeconômico do aluno, variáveis referentes à infraestrutura e aos equipamentos escolares estão entre os preditores de bons desempenhos dos alunos (Barbosa e Fernandes, 2001; Jesus \& Laros, 2004). Além disso, os estudos brasileiros demonstram que outras variáveis do nível da escola afetam o desempenho, tais como: recursos técnicopedagógicos, lição de casa, comprometimento dos professores, alta expectativa dos professores em relação aos alunos, formação dos professores (ANDRADE \&
Laros, 2007; Barbosa \& Fernandes, 2001; Jesus \& Laros, 2004; SoAREs, 2004; SoAres; CÉsAr \& MAMbrini, 2001).

Como apontado por Mello (1994), não há dúvidas de que a escola pode fazer a diferença, mas ainda não há consenso ou pleno entendimento acerca do que proporciona essa diferença e como atuar para diminuí-la. Por isso, os estudos na área de fatores contextuais continuam sendo desenvolvidos e ainda se faz necessário investir esforços em aprimorar a forma de mensurar os fatores contextuais.

$\mathrm{Na}$ perspectiva de buscar melhores formas de mensurar fatores contextuais, em uma publicação recente, foi desenvolvida uma escala de infraestrutura escolar, utilizando-se os dados do Censo Escolar de 2011 (Soares Neto; Jesus; Karino \& Andrade, 2013). Nesse estudo, quatro níveis de infraestrutura foram estabelecidos: elementar, básico, adequado e avançado.

Essa escala de infraestrutura possibilita análises relevantes da realidade das escolas brasileiras de forma simples, possibilitando o planejamento de políticas públicas para a melhoria da educação do país. Há de se considerar, ainda, que estudos já demonstraram que as condições físicas e o ambiente escolar são variáveis que impactam a proficiência em todas as regiões brasileiras, e que há uma forte correlação entre infraestrutura e nível socioeconômico (BARBosa et al., 2001).

Tendo como base os dados do Censo Escolar de 2011, verificou-se que 44,5\% das escolas brasileiras possuem infraestrutura elementar e que grande parte delas está na área rural das regiões Norte e Nordeste. Essas escolas são responsáveis por mais de 7 milhões de matrículas (Soares Neto; Jesus; Karino \& Andrade, 2013). Esses resultados demonstram o 
quanto ainda é preciso investir em infraestrutura escolar no Brasil e que estudos descritivos podem contribuir para tornar mais transparente aos gestores essa realidade.

Detectar problemas é importante, propor caminhos para solucioná-los é mais importante ainda. Com o objetivo de desenhar estratégias, no presente trabalho, apresentamos uma análise que leva em consideração o tamanho das escolas e suas infraestruturas. Como será detalhado no corpo do artigo, a correlação entre infraestrutura e tamanho da escola é relativamente alta. O significado disto é que, em geral, as escolas maiores têm infraestruturas melhores.

Considerando que os problemas são diferentes para escolas de diferentes tamanhos e, mais importante, as soluções para os problemas existentes são igualmente diversas, o estudo buscará focar nas escolas que precisam de uma atuação mais urgente. Assim, buscar-se-á analisar as características das escolas menores, em especial as com até 200 alunos e até 10 turmas, uma vez que elas, em sua maioria, apresentam uma infraestrutura precária.

\section{Metodologia}

O tamanho da escola pode ser medido pelo número de turmas ou pela quantidade de matrículas. Utilizando essas duas medidas, serão consideradas neste estudo escolas com até 10 turmas e até 200 matrículas. O recorte atribuído no estudo teve como base a visão de que uma escola que atende até 200 alunos pode ser considerada como pequena. Além disso, em média, essas escolas terão 20 alunos por turma, o que se aproxima do critério utilizado pela Prova Brasil para definir escolas pequenas. Nessa avaliação, escolas que possuem menos de
20 alunos na série avaliada não constituem o universo de escolas que terá aplicação. Por outro lado, não se tinha como intuito usar exatamente o mesmo critério da Prova Brasil, pois isso excluiria do estudo um importante aspecto a ser analisado nessas escolas: o nível de desempenho.

Outro fator considerado foi o percentual de alunos brasileiros que essas escolas de pequeno porte atendem. Do total de 194.932 escolas brasileiras, 157.381

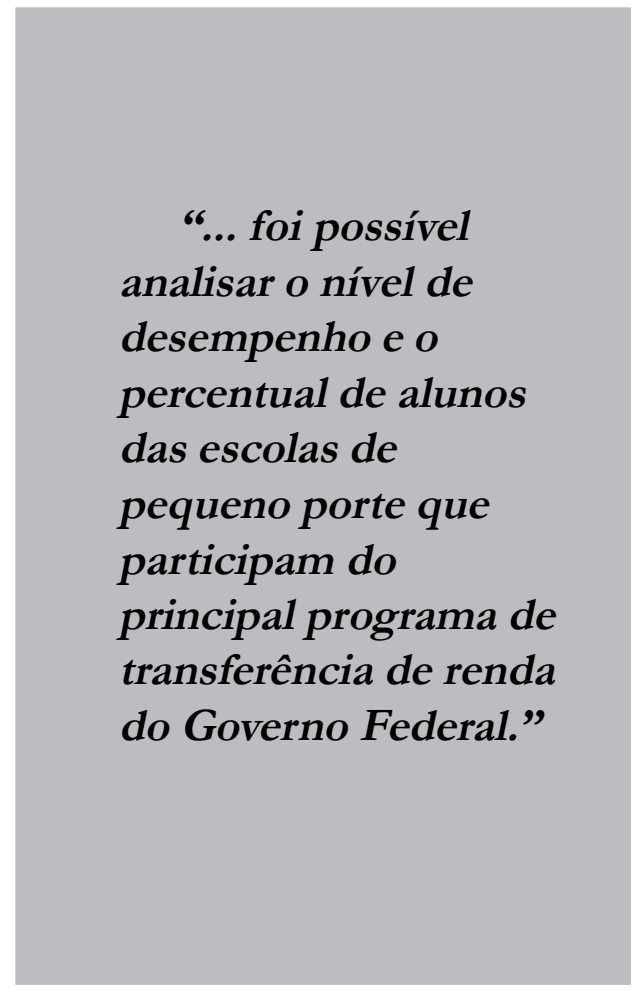

são públicas; 90.379 foram categorizadas como escolas de pequeno porte e são responsáveis por 5.724.970 de matrículas, do total de 54.436.318 de todo o ensino básico do País. Ou seja, essas escolas, denominadas aqui de pequeno porte, representam cerca de $46 \%$ das escolas brasileiras, e são responsáveis por cerca de $10 \%$ do total de alunos matriculados no País. 
Quanto aos instrumentos, será utilizada uma escala de infraestrutura escolar construída por meio da Teoria de Resposta ao Item (TRI) e com base no Censo Escolar da Educação Básica de 2011, realizado pelo Instituto Nacional de Estudos e Pesquisas Educacionais Anísio Teixeira (Inep). O Censo da Educação Básica Brasileira coleta anualmente dados a respeito das escolas, das turmas, dos docentes e dos alunos brasileiros. Os dados utilizados para a construção da escala foram extraídos do Censo Escolar de 2011 e são provenientes do formulário "Cadastro das Escolas", que contempla os fatores denominados "Caracterização e Infraestrutura" e "Equipamentos".

A Teoria de Resposta ao Item (TRI) constitui uma família de metodologias estatísticas que tem como característica o fato de oferecer um caminho sólido do ponto de vista teórico para, a partir de um conjunto de itens pertencentes a uma prova ou a um questionário, construir uma escala (AyALA, 2009). $\mathrm{Na}$ atualidade, a TRI tem sido bastante utilizada para o desenvolvimento de escalas de proficiência. Importantes avaliações educacionais brasileiras, como o SAEB, a Prova Brasil e o Enem, têm como base essa teoria para o cálculo da proficiência dos alunos. Em publicação recente, Soares Neto e colaboradores (SoARes Neto; Jesus; Karino \& ANDRADE, 2013) fizeram uso da TRI para construírem uma escala de infraestrutura das escolas brasileiras ${ }^{1}$. No presente estudo, tal escala será aplicada nas análises.

A escala de infraestrutura das escolas de educação básica brasileira utiliza 24 itens, que são apresentados na Tabela 1, e foi obtida tendo como referência as 194.932 escolas que responderam ao Censo Escolar de 2011.

Para a obtenção da escala, estabeleceuse o valor médio de infraestrutura dessas

Tabela 1: Itens utilizados para a construção da escala de infraestrutura das escolas brasileiras

\begin{tabular}{c|l|c|l}
\hline Item & Descrição do Item & Item & Descrição do Item \\
\hline 1 & Água consumida pelos alunos & 13 & Parque infantil \\
\hline 2 & Abastecimento de água & 14 & Berçário \\
\hline 3 & Abastecimento de energia elétrica & 15 & Sanitário fora ou dentro do prédio \\
\hline 4 & Esgoto sanitário & 16 & Sanitário para educação infantil \\
\hline 5 & Sala de diretoria & 17 & Sanitário para deficientes físicos \\
\hline 6 & Sala de professor & 18 & Dependências para deficientes físicos \\
\hline 7 & Laboratório de informática & 19 & TV \\
\hline 8 & Laboratório de ciências & 20 & DVD \\
\hline 9 & Sala de atendimento especial & 21 & Copiadora \\
\hline 10 & Quadra de esportes coberta/descoberta & 22 & Impressora \\
\hline 11 & Cozinha & 23 & Computadores \\
\hline 12 & Biblioteca & 24 & Internet \\
\hline
\end{tabular}

Fonte: Soares Neto, Jesus, Karino \& Andrade (2013). Uma Escala para Medir a Infraestrutura Escolar. Estudos em Avaliação Educacional, 54(24), 78-99. 
escolas como 50 e para o desvio-padrão da distribuição, o valor 10 .

A Tabela 2, a seguir, mostra a distribuição das escolas brasileiras nos níveis de infraestrutura estabelecidos pela escala.
O presente estudo também fez uso, além da escala de infraestrutura, de dados de duas outras bases - microdados da Prova Brasil 2011 e base do Programa Bolsa Família -, disponibilizadas pelo

Tabela 2: Descrição dos níveis e percentual de escolas por intervalo de proficiência da escala de infraestrutura escolar

\begin{tabular}{|c|c|c|}
\hline Nível & $\begin{array}{l}\text { Percentual } \\
\text { de escolas }\end{array}$ & Descrição dos níveis de infraestrutura \\
\hline 1 - Infraestrutura elementar & 44,5 & $\begin{array}{l}\text { Infraestrutura escolar elementar: estão neste } \\
\text { nível escolas que possuem somente aspectos } \\
\text { de infraestrutura elementares para o funcio- } \\
\text { namento de uma escola, tais como água, } \\
\text { sanitário, energia, esgoto e cozinha. }\end{array}$ \\
\hline 2 - Infraestrutura básica & 40,0 & $\begin{array}{l}\text { Infraestrutura escolar básica: além dos itens } \\
\text { presentes no nível anterior, neste nível as } \\
\text { escolas já possuem uma infraestrutura básica, } \\
\text { típica de unidades escolares. Em geral, elas } \\
\text { possuem: sala de diretoria e equipamentos } \\
\text { como TV, DVD, computadores e impressora. }\end{array}$ \\
\hline 3 - Infraestrutura adequada & 14,9 & $\begin{array}{l}\text { Infraestrutura escolar adequada: além dos } \\
\text { itens presentes nos níveis anteriores, as escolas } \\
\text { deste nível, em geral, possuem uma infra- } \\
\text { estrutura mais completa, o que permite um } \\
\text { ambiente mais propício para o ensino e apren- } \\
\text { dizagem. Essas escolas possuem, por exem- } \\
\text { plo, espaços como sala de professores, biblio- } \\
\text { teca, laboratório de informática e sanitário } \\
\text { para educação infantil. Há também espaços } \\
\text { que permitem o convívio social e o desen- } \\
\text { volvimento motor, tais como quadra espor- } \\
\text { tiva e parque infantil. Além disso, são escolas } \\
\text { que possuem equipamentos complementares, } \\
\text { como copiadora e acesso a internet. }\end{array}$ \\
\hline 4 - Infraestrutura avançada & 0,6 & $\begin{array}{l}\text { Infraestrutura escolar avançada: as escolas } \\
\text { neste nível, além dos itens presentes nos níveis } \\
\text { anteriores, possuem uma infraestrutura } \\
\text { escolar mais robusta e mais próxima do ideal, } \\
\text { com a presença de laboratório de ciências e } \\
\text { dependências adequadas para atender a } \\
\text { estudantes com necessidades especiais. }\end{array}$ \\
\hline
\end{tabular}

Fonte: Soares Neto, Jesus, Karino \& Andrade (2013). Uma Escala para Medir a Infraestrutura Escolar. Estudos em Avaliação Educacional, 54(24), 78-99. 
INEP e Ministério do Desenvolvimento Social (MDS), respectivamente. A partir dessas bases, foi possível analisar o nível de desempenho e o percentual de alunos das escolas de pequeno porte que participam do principal programa de transferência de renda do Governo Federal.

\section{O tamanho e a infraestrutura das escolas brasileiras}

Nesta seção, será feito um estudo a respeito do tamanho das escolas públicas de ensino básico brasileiras. A Tabela 3, a seguir, mostra a distribuição das escolas públicas de ensino básico em relação às suas infraestruturas. Ao se considerar somente as escolas públicas, nota-se que $51,8 \%$ delas têm infraestrutura na categoria elementar e essas escolas são responsáveis pela educação de mais de 6 milhões de estudantes, o que representa $14,4 \%$ dos matriculados.

Com base nesse resultado, pode-se indagar os meios para se garantir uma educação de qualidade em um ambiente desprovido de condições mínimas de infraestrutura. Todavia, para se caminhar no sentido da solução do problema da melhoria das condições materiais das escolas, deve-se estudar a viabilidade econômica de se prover a mesma infraestrutura de uma escola de um centro urbano em uma escola localizada em um município do interior com poucos habitantes.

A Tabela 4 mostra a distribuição das 157.381 escolas públicas em relação a duas variáveis: quantidade de matrículas e quantidade de turmas.

Como pode ser observado, aquelas escolas com até 200 matrículas e com até 10 turmas somam 90.379, ou seja, 57\% das escolas públicas do País. Elas constituem o foco principal do presente trabalho.

A Tabela 5, a seguir, mostra a distribuição das escolas públicas, e das públicas de até 200 alunos e até 10 turmas, em relação à dependência administrativa.

Nota-se que as escolas municipais representam 79,2\% do total de escolas públicas, e 92,5\% do total das escolas de pequeno porte.

Tabela 3: Distribuição das escolas públicas brasileiras em relação às suas infraestruturas

\begin{tabular}{l|c|c|c|c}
\hline $\begin{array}{c}\text { Níveis de } \\
\text { infraestrutura }\end{array}$ & $\begin{array}{c}\text { Quantidade de } \\
\text { escolas públicas }\end{array}$ & $\begin{array}{c}\text { Percentual } \\
\text { de escolas } \\
\text { públicas }\end{array}$ & $\begin{array}{c}\text { Quantidade } \\
\text { de estudantes } \\
\text { matriculados }\end{array}$ & $\begin{array}{c}\text { Percentual de } \\
\text { estudantes } \\
\text { matriculados }\end{array}$ \\
\hline Elementar & 81.502 & 51,8 & 6.682 .827 & $14,4 \%$ \\
\hline Básico & 56.131 & 35,7 & 23.864 .682 & $51,5 \%$ \\
\hline Adequado & 18.949 & 12,0 & 14.968 .775 & $32,3 \%$ \\
\hline Avançado & 799 & 0,5 & 846.791 & $1,8 \%$ \\
\hline Total & 157.381 & $100 \%$ & 46.363 .075 & $100 \%$ \\
\hline
\end{tabular}

Fonte: Elaborado pelos autores, a partir de dados do Censo Escolar da Educação Básica 2011/INEP. 
Tabela 4: Quantidade de escolas em relação ao número de turmas e ao número de matrículas das escolas públicas de ensino básico brasileiras

\begin{tabular}{l|c|c|c|c} 
& $\begin{array}{c}\text { Até 200 } \\
\text { matrículas }\end{array}$ & $\begin{array}{c}\text { De 201 a 500 } \\
\text { matrículas }\end{array}$ & $\begin{array}{c}\text { De 501 até } \\
\mathbf{1 0 0 0} \\
\text { matrículas }\end{array}$ & $\begin{array}{c}\text { Mais de 1000 } \\
\text { matrículas }\end{array}$ \\
\hline Até 10 turmas & 90.379 & 5.101 & 61 & 65 \\
\hline $\begin{array}{l}\text { De 11 a 50 } \\
\text { turmas }\end{array}$ & 3.767 & 26.674 & 20.722 & 7.576 \\
\hline $\begin{array}{l}\text { De 51 a 100 } \\
\text { turmas }\end{array}$ & 5 & 27 & 180 & 2.700 \\
\hline $\begin{array}{l}\text { Mais de 100 } \\
\text { turmas }\end{array}$ & 0 & 2 & 5 & 117 \\
\hline
\end{tabular}

Fonte: Elaborado pelos autores, a partir de dados do Censo Escolar da Educação Básica 2011/INEP.

Tabela 5: Distribuição das escolas públicas de ensino básico e das escolas públicas de ensino básico de pequeno porte em relação à variável dependência adminis trativa

\begin{tabular}{c|c|c}
\hline $\begin{array}{c}\text { Dependência } \\
\text { administrativa }\end{array}$ & $\begin{array}{c}\text { Escolas públicas } \\
\text { em geral }\end{array}$ & $\begin{array}{c}\text { Escolas públicas com até 10 } \\
\text { turmas e até 200 alunos }\end{array}$ \\
\hline Federal & 451 & 93 \\
\hline Estadual & 32.316 & 6.700 \\
\hline Municipal & 124.614 & 83.586 \\
\hline Total & 157.381 & 90.379 \\
\hline
\end{tabular}

Fonte: Elaborado pelos autores, a partir de dados do Censo Escolar da Educação Básica 2011/INEP.

Características das escolas de até 10 turmas e até 200 alunos

A Tabela 6, a seguir, mostra que o extrato de escolas em estudo apresenta uma infraestrutura bastante precária. Verifica-se que $80,5 \%$ delas estão no limite inferior das categorias de infraestrutura.

Nesse ponto de nossa análise, cabe ressaltar que, do total de 194.932 escolas brasileiras, 86.739 (categorizadas como escolas de pequeno porte no presente estudo) estão na categoria elementar de infraestrutura e observa-se que dessas, 72.751 são escolas públicas de pequeno porte. Ou seja, do total de escolas de pequeno porte com infraestrutura elementar, $84 \%$ são públicas. A Tabela 6 também mostra o quantitativo de escolas privadas de pequeno porte, para que se possa verificar a discrepância em termos de infraestrutura entre as escolas públicas e as privadas. Nota-se que apenas $22 \%$ das escolas privadas de pequeno porte têm infraestrutura elementar. Apesar de as escolas privadas possuírem, em geral, 
Tabela 6: Categorias de infraestrutura das escolas brasileiras

\begin{tabular}{c|c|c|c}
$\begin{array}{c}\text { Categoria de } \\
\text { infraestrutura }\end{array}$ & $\begin{array}{c}\text { Quantidade de } \\
\text { escolas públicas }+ \\
\text { privadas }\end{array}$ & $\begin{array}{c}\text { Quantidade de } \\
\text { escolas públicas } \\
\text { de pequeno porte }\end{array}$ & $\begin{array}{c}\text { Quantidade de } \\
\text { escolas privadas } \\
\text { de pequeno porte }\end{array}$ \\
\hline Elementar & 86.739 & 72.751 & 4.665 \\
\hline Básica & 78.047 & 16.655 & 14.003 \\
\hline Adequada & 29.026 & 963 & 2.265 \\
\hline Avançada & 1.120 & 10 & 39 \\
\hline Total & 194.932 & 90.379 & 20.972 \\
\hline
\end{tabular}

Fonte: Elaborado pelos autores, a partir de dados do Censo Escolar da Educação Básica 2011/INEP.

condições melhores de infraestrutura, destaca-se que existem mais de 4.600 escolas privadas de pequeno porte com infraestrutura elementar no Brasil.

Para se verificar como estão distribuídas geograficamente, o Gráfico 1 a seguir mostra o número absoluto de escolas de pequeno porte em relação aos Estados da Federação. Os Estados da Bahia, do Maranhão e do Pará contêm o maior número dessas escolas. Como a quantidade é bastante diferente entre os estados brasileiros, o Gráfico 2 traz uma distribuição percentual. Claramente, os Estados do Norte e Nordeste mostram um maior percentual de escolas de pequeno porte em relação às outras regiões da Federação.

A Tabela 7, mostra que $73 \%$ das escolas de pequeno porte estão na região rural do País. Assim, vai se desenhando uma característica bem definida da categoria de escolas de pequeno porte: são escolas com infraestrutura bastante precária e que se localizam, em sua maioria, em locais específicos do País.

Indo adiante na análise (Tabela 8), verifica-se que a média de desempenho na Prova Brasil das escolas de pequeno porte também é inferior à média nacional, tanto para língua portuguesa quanto para matemática, para ambas as séries avaliadas nesse exame.

Finalmente, para completar o estudo, é apresentada em dois gráficos a frequência de escolas que recebem alunos provenientes de famílias beneficiadas pelo Programa Bolsa Família. O Gráfico 3 é relativo a todas as escolas públicas do País, enquanto que o Gráfico 4 mostra a distribuição dos alunos nas escolas da categoria de pequeno porte. Como se vê, a distribuição é basicamente invertida, ou seja, as escolas de pequeno porte tendem a ter um maior percentual de alunos provenientes de famílias beneficiadas pelo Programa Bolsa Família.

As 157.381 escolas públicas recebem um total de 14.513.407 de alunos cujas famílias recebem o benefício do Bolsa Família; isso corresponde a 31\% dos alunos das escolas públicas.

As 90.379 escolas de até 10 turmas e até 200 alunos recebem um total de 2.209.761 de alunos cujas famílias recebem o benefício do Bolsa Família; isso significa 39\% do total de matrículas nessas escolas. 


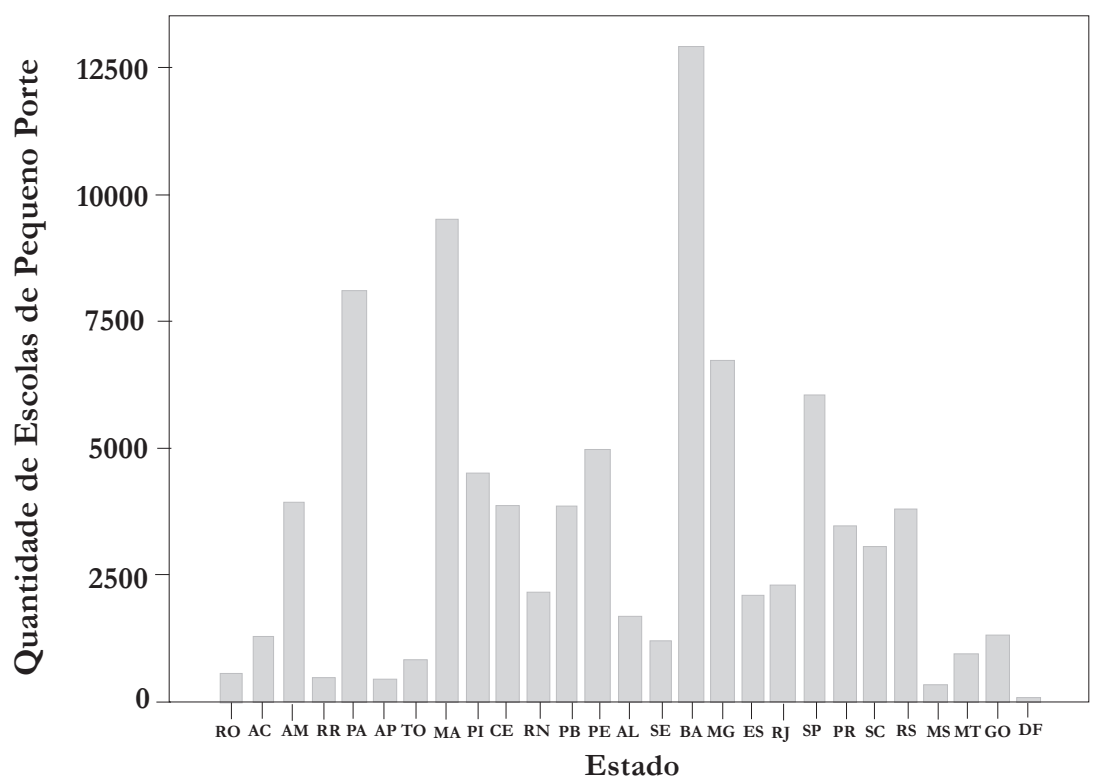

Fonte: Elaborado pelos autores, a partir de dados do Censo Escolar da Educação Básica 2011/INEP.

Gráfico 1: Distribuição das escolas de pequeno porte em relação aos estados brasileiros

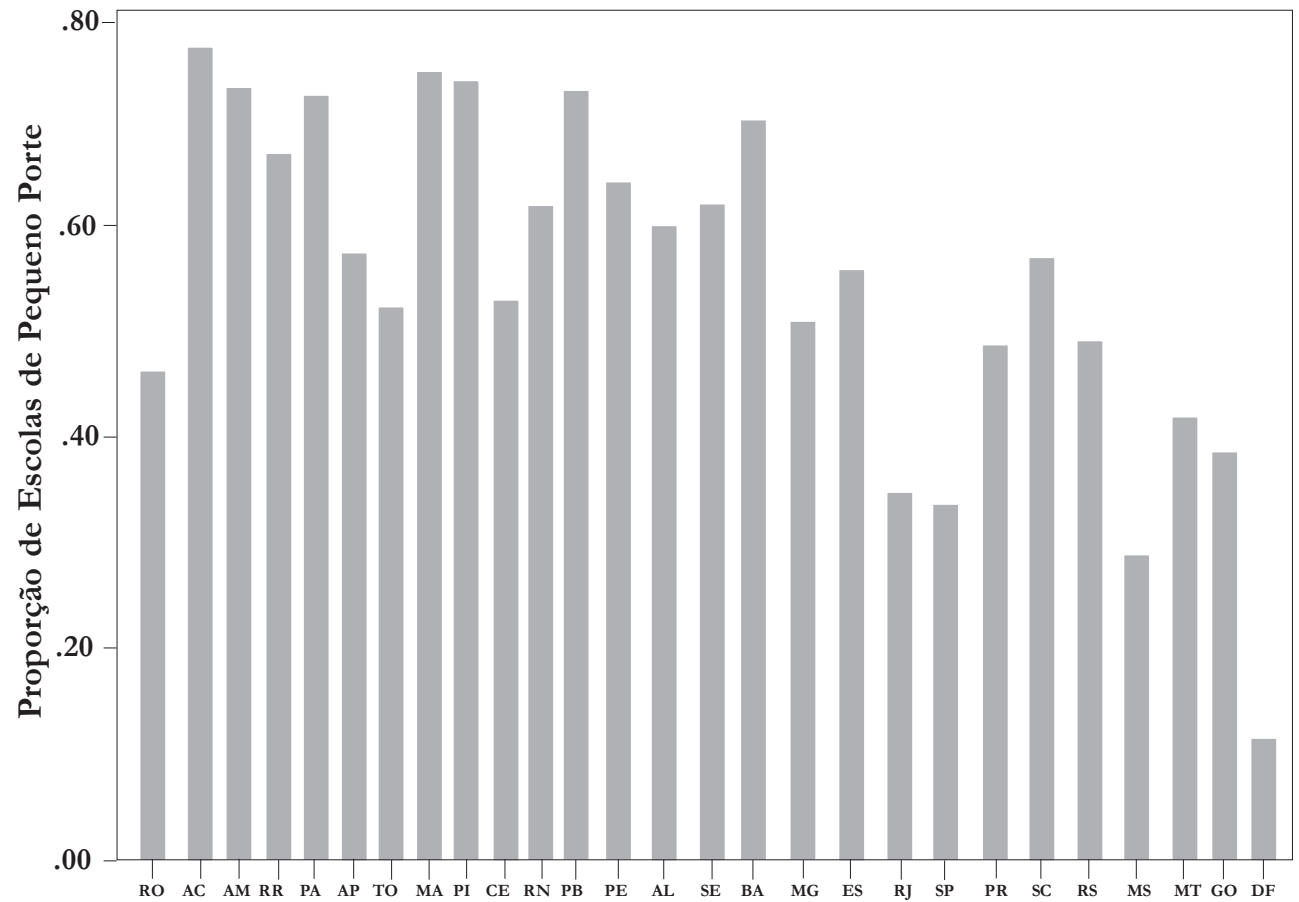

Fonte: Elaborado pelos autores, a partir de dados do Censo Escolar da Educação Básica 2011/INEP.

Gráfico 2: Proporção das escolas de cada unidade da Federação que são de pequeno porte 
Tabela 7: Distribuição das escolas públicas de pequeno porte em relação à loca lização urbana ou rural

\begin{tabular}{c|c|c}
\hline Localização das escolas & Quantidade de escolas & Percentual de escolas \\
\hline Urbana & 24.365 & 27,0 \\
\hline Rural & 66.014 & 73,0 \\
\hline Total & 90.379 & 100,0 \\
\hline
\end{tabular}

Fonte: Elaborado pelos autores, a partir de dados do Censo Escolar da Educação Básica 2011/INEP.

Tabela 8: Comparação das médias na Prova Brasil entre todas as escolas públi cas e as escolas públicas de pequeno porte

\begin{tabular}{c|c|c|c|c}
\hline & \multicolumn{2}{|c|}{ Média na Prova Brasil de 2011 } & \multicolumn{2}{c}{ Média na Prova Brasil de 2011 } \\
$\mathbf{5}^{\mathbf{0}}$ Ano & \multicolumn{2}{c}{$\mathbf{9}^{\circ}$ Ano } \\
\hline Disciplina & $\begin{array}{c}\text { Todas as } \\
\text { escolas } \\
\text { públicas }\end{array}$ & $\begin{array}{c}\text { Escolas públicas } \\
\text { de pequeno } \\
\text { porte }\end{array}$ & $\begin{array}{c}\text { Todas as } \\
\text { escolas } \\
\text { públicas }\end{array}$ & $\begin{array}{c}\text { Escolas públicas } \\
\text { de pequeno } \\
\text { porte }\end{array}$ \\
\hline Língua Portuguesa & 184 & 174 & 236 & 225 \\
\hline Matemática & 203 & 192 & 243 & 235 \\
\hline
\end{tabular}

Fonte: Elaborado pelos autores, a partir dos Microdados da Prova Brasil 2011/INEP.

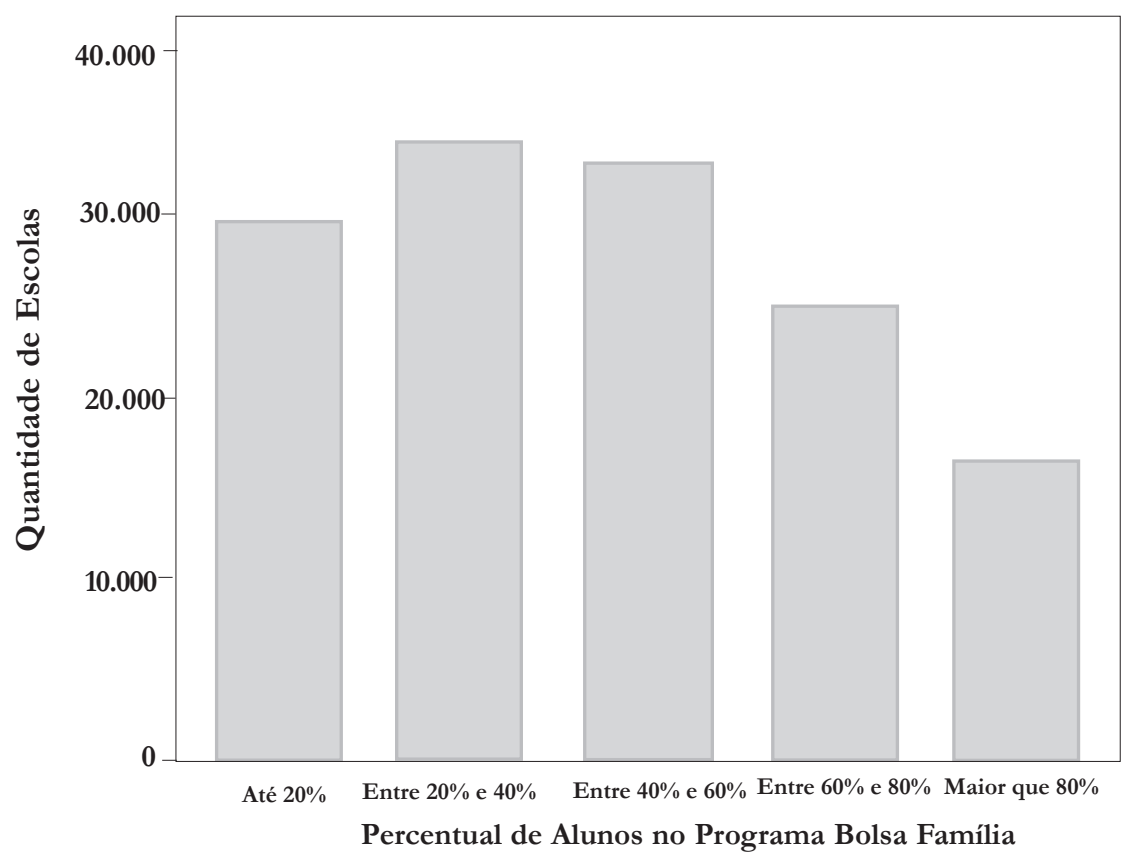

Fonte: Elaborado pelos autores, a partir de dados do Programa Bolsa Família/MDS.

Gráfico 3: Quantidade de escolas públicas onde estudam alunos de famílias beneficiárias do Programa Bolsa Família 


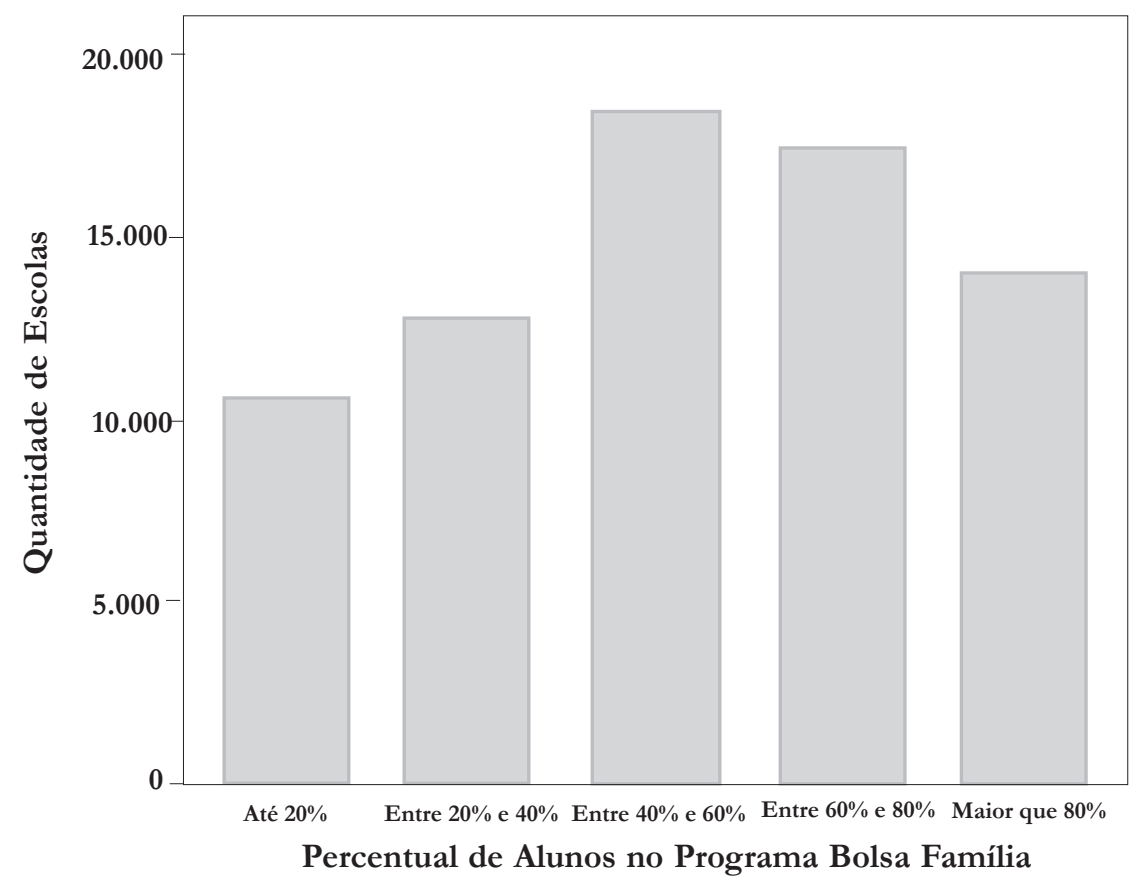

Fonte: Elaborado pelos autores, a partir de dados do Programa Bolsa Família/MDS.

Gráfico 4: Quantidade de escolas públicas de até 10 turmas e até 200 alunos em função do percentual de alunos provenientes de famílias beneficiárias do Programa Bolsa Família

\section{Conclusões}

O presente trabalho foca em escolas públicas brasileiras que têm até 200 alunos e até 10 turmas. Como apresentado, essas escolas se colocam em uma categoria que merece estratégias particulares para propiciar aos seus alunos uma educação de qualidade. Em geral, elas se localizam na zona rural das regiões Norte e Nordeste e têm uma infraestrutura elementar. Elas são responsáveis por $11 \%$ das crianças que frequentam o ensino básico e, na Prova Brasil, essas escolas apresentam desempenho inferior à média nacional.

Esses resultados corroboram com os estudos que demonstram a relação entre infraestrutura, nível socioeconômico e desempenho dos estudantes (BARBOSA et al., 2001; ANDRAdE \& Laros, 2007; Barbosa \& Fernandes, 2001; Jesus \& Laros, 2004; SoAres, César \& Mambrini, 2001; Willms \& Somers, 2000). Todavia, deve-se ressaltar que as análises aqui realizadas são de cunho correlacional, sem qualquer relação de causalidade; tratam-se de análises descritivas com dados populacionais, não fazendo qualquer referência à estatística inferencial. Assim, destaca-se a relevância do desenvolvimento de estudos causais, fazendo uso de outras técnicas e metodologias.

Devido às particularidades relativas à localização e à quantidade de alunos atendidos nessas escolas, políticas públicas específicas para a melhoria da educação devem ser planejadas e executadas, a fim 
de garantir uma educação de qualidade para mais de 5 milhões de estudantes que dependem dessas escolas para a conquista de um futuro melhor. Pois, ao procurarem uma escola para frequentar, sofrem o efeito de seletividade, uma vez que são pré-selecionados para um determinado tipo de escola, que fica localizada mais próxima à sua residência.

Deve-se ressaltar que, conforme definido na Constituição Federal, a educação é um direito de todos os brasileiros e, conforme o Art. 206, o ensino deve ser ministrado tendo como base a igualdade de condições para o acesso e a permanência na escola. Ao focar as escolas de até 10 turmas e até 200 alunos, busca-se tornar mais transparente a realidade dessas escolas e, ao caracterizá-las, espera-se contribuir para essas ações específicas.

A partir das análises deste estudo, verificou-se que as escolas de até 10 turmas e até 200 alunos atendem a alunos de regiões mais isoladas, de tal forma que muitos equipamentos escolares não podem ser disponibilizados devido aos custos. Para esses casos, soluções viáveis economicamente devem ser buscadas. Não se trata somente de comprar equipamentos; prover condições de infraestrutura envolve condições físicas como energia e água, além de condições de uso e manutenção dos equipamentos.

A solução não é fácil. É preciso compreender o que seria uma infraestrutura ideal para essas escolas de até 10 turmas e até 200 alunos, que seja viável economicamente, passível de manutenção e suficiente para o desenvolvimento adequado das práticas pedagógicas.

Dessa forma, espera-se que este trabalho dê abertura a uma reflexão acadêmica, econômica e política. Consequentemente, espera-se que essa reflexão possa subsidiar políticas públicas voltadas ao atendimento da realidade destacada neste artigo.

(Artigo recebido em julho de 2013. Versão final em setembro de 2013).

\section{Nota}

${ }^{1}$ Maiores detalhes da escala encontram-se no artigo "Uma escala para medir a infraestrutura escolar” (Soares Neto; Jesus; Karino \& Andrade, 2013).

\section{Referências bibliográficas}

Andrade, J. M., de; Laros, J. A. Fatores associados ao desempenho escolar: um estudo multinível com dados do SAEB/2001. Psicologia: Teoria e Pesquisa, v. 23, n. 1, p. 33-42, 2007. Ayala, R. J. de. The Theory and Practice of Iten Response Theory. The Guilford Press, 2009. Barbosa, M. E. F.; Beltrão, K. I.; Fariñas, M. S.; Fernandes, C.; Santos, D. Modelagem do Saeb - 99: Modelos Multinível. Relatório Técnico, Rio de Janeiro, 2001. 
Barbosa, M. E. F.; Fernandes, C. A escola brasileira faz diferença? Uma investigação dos efeitos da escola na proficiência em matemática dos alunos da $4^{a}$ série. In: C. Franco (Ed.). Avaliação, ciclos e promoção na educação. Porto Alegre: Artmed, 2001. p. 155-172.

Coleman, J. S. et al. Equality of educational opportunity. Washington: Government Printing Office, 1966.

Fletcher, P. R. À procura do ensino eficaz: (Relatório Técnico). Brasília: MEC-DAEB, 1998.

Jesus, G. R., \& Laros, J. A. Eficácia escolar: regressão multinível com dados de avaliação em larga escala. Avaliação Psicológica, v. 3, n. 2, p. 93-106, 2004.

LEE, V. L. Utilização de modelos lineares hierárquicos lineares para estudar contextos sociais: o caso dos efeitos da escola. In: N. Brooke e J. F. SoAres (Ed.). Pesquisa em eficácia escolar: origem e trajetórias. Belo Horizonte: Editora UFMG, 2008. p. 273-296

Mello, G. N. Escolas eficazes: um tema revisitado. In: Xavier, A. C. et al. (Org.) Gestão Escolar: desafios e tendências. Brasília: Ipea, 1994. p. 329-369.

Sammons, P. School Effectiveness: Coming of Age in the 21st Century. Taylor \& Francis Group. 1999.

SOARES, J. F. O efeito da escola no desempenho cognitivo de seus alunos. Revista Electrónica Iberoamericana sobre Calidad, Eficacia y Cambio en Educación, v. 2, n. 2, p. 1-17, 2004.

SoARes, J. F.; Andrade, R. J. de. Nível socioeconômico, qualidade e equidade das escolas de Belo Horizonte. Ensaio: Avaliação Política Pública Educacional, 14(50), p. 107-126, 2006.

SoAres, J. F.; César, C. C.; Mambrini, J. Determinantes de desempenho dos alunos do ensino básico brasileiro: evidências do SAEB de 1997. In: C. Franco (Ed.). Avaliação, ciclos e promoção na educação. Porto Alegre: Artmed, 2001. p. 121-153.

Soares Neto, J. J.; Jesus, G. R.; Karino, C. A.; Andrade, D. F. Uma Escala para Medir a Infraestrutura Escolar. Estudos em Avaliação Educacional, v. 54, n. 24, p. 78-99, 2013.

WiLLms, J. D.; Somers, M. Family, classroom, and school effects on children's educational outcomes in Latin America. School Effectiveness and School Improvement, v. 12, n. 4, p. 409445, 2000. 


\section{Resumo - Resumen - Abstract}

\section{A infraestrutura das escolas públicas brasileiras de pequeno porte \\ Joaquim José Soares Neto, Camila Akemi Karino, Girlene Ribeiro de Jesus e Dalton Francisco de Andrade}

Em um país como o Brasil, buscar a equidade da educação pública é um grande desafio. Para ser vencido, é necessária a adoção de políticas públicas adequadas, que considerem a realidade tanto de escolas grandes quanto de escolas menores, pois elas apresentam necessidades e características distintas. Nesse contexto, este artigo teve como objetivo estudar a infraestrutura das escolas brasileiras com até 10 turmas e com até 200 alunos, a fim de prover uma análise dessa realidade pouco investigada. Verificou-se que essas escolas representam $46 \%$ do total das escolas de ensino básico brasileiro e são responsáveis por aproximadamente $11 \%$ das matrículas do País nesse nível de ensino. Em geral, elas têm um padrão de infraestrutura precário, média de desempenho na Prova Brasil abaixo da média nacional e estão localizadas, em sua maioria, na área rural das regiões Norte e Nordeste do País. Nelas estudam 5.724.970 de alunos, sendo que 2.209.761 são alunos cujas famílias recebem o benefício do Bolsa Família. Conclui-se que investigar a realidade dessas escolas é essencial ao possibilitar ações específicas para atender a esse público e, com isso, promover uma educação de qualidade para todos.

Palavras chave: infraestrutura escolar; Teoria de Resposta ao Item (TRI); avaliação educacional

\section{La infraestructura de las escuelas públicas brasileñas de tamaño pequeño Joaquim José Soares Neto, Camila Akemi Karino, Girlene Ribeiro de Jesus y Dalton Francisco de Andrade}

En un país como Brasil, en busca de la equidad de la educación pública es un reto importante. Para ser superados, es necesario adoptar políticas apropiadas para considerar la realidad de los dos grandes escuelas, escuelas mucho más pequeñas porque tienen necesidades y características. En este contexto, el presente trabajo tiene como objetivo estudiar la infraestructura de las escuelas brasileñas con un máximo de 10 clases y 200 alumnos, con el fin de proporcionar un análisis de esa realidad poco investigado. Se encontró que estas escuelas representan el 46\% de las escuelas primarias brasileñas totales y son responsables de aproximadamente el $11 \%$ de la matrícula en el país en ese nivel de educación. En general, tienen un patrón de mala infraestructura, el rendimiento promedio en Brasil prueba por debajo de la media nacional y se encuentran principalmente en las zonas rurales del norte y el nordeste. Allí, estudian 5.724.970 estudiantes y 2.209.761 son estudiantes cuyas familias reciben el beneficio de la Bolsa Família. Llegamos a la conclusión de que investigue la realidad de estas escuelas, es esencial para permitir acciones específicas para hacer frente a esta audiencia y con ello promover la educación de calidad para todos.

Palabras clave: infraestructura de las escuelas; Teoría de respuesta al item (TRI); evaluación educativa

\section{The infrastructure of small public schools in Brazil Joaquim José Soares Neto, Camila Akemi Karino, Girlene Ribeiro de Jesus and Dalton Francisco de Andrade}

In a country like Brazil, seeking equity of public education is a major challenge. To be overcome, it is necessary to adopt appropriate policy to consider the reality of both great schools and small schools because they have different needs and characteristics. In this context, this paper aims to study the infrastructure of Brazilian schools with up to 10 classes and 200 students, 
in order to provide an analysis of that reality poorly investigated. It was found that these schools represent $46 \%$ of total Brazilian primary schools and are responsible for approximately $11 \%$ of enrollments in the country at that level of education. In general, they have a pattern of poor infrastructure, average performance in "Prova Brasil" below the national average and are located mostly in rural areas of the North and Northeast Regions. In these schools there are 5,724,970 students and 2,209,761 are students whose families receive the benefit of the "Bolsa Família". We conclude that investigate the reality of these schools, it is essential to allow specific actions to address this audience and thereby promote quality education for all.

Keywords: scholar infrastructure; Item Response Theory (IRT); educational evaluation

Joaquim José Soares Neto

É doutor em Química Teórica, pela Aarhus Universitet (Dinamarca) e pós-doutor pelo California Institute of Technology (Califórnia, EUA). Atualmente é professor titular da Universidade de Brasília (UnB) e membro do programa de pósgraduação em Desenvolvimento, Sociedade e Cooperação Internacional do Centro de Estudos Avançados Multidisciplinares (Ceam/UnB).Contato: jisoaresneto@gmail.com

Camila Akemi Karino

É doutoranda do Instituto de Pssicologia da Universidade de Brasília (UnB) e coordenadora-geral de Instrumentos e Medidas do Instituto Nacional de Estudos e Pesquisas Educacionais (INEP). Contato: camilaakarino@gmail.com

Girlene Ribeiro de Jesus

É doutora em Psicologia Social, do Trabalho e das Organizações, pela Universidade de Brasília (UnB) e professora adjunta da faculdade de Educação da UnB. Contato: girlene@unb.br

Dalton Francisco de Andrade

É doutor em Biostatistics, pela University of North Carolina at Chapel Hill, NC (EUA). Professor titular aposentado da Universidade Federal de Santa Catarina (UFSC). No momento, atua como professor voluntário do Departamento de Engenharia da Produção da USFC. Contato: dalton.andrade@ufsc.br 